\title{
Cardiac Auscultation Versus Two-Dimensional Transthoracic Echocardiography for detection of Valve Disease in Erbil City
}

\author{
Aree Nadhem A. Daham ${ }^{1}$, Mohammed Hasan Al-Meshhadani², Nicola King ${ }^{3 *}$ \\ ${ }^{1}$ Ministry of Health, Cardiac Center, Erbil City, Iraq \\ ${ }^{2}$ Hawler Medical University, Medical College, Department of Medicine, Erbil City, Iraq \\ ${ }^{3}$ School of Biomedical and Healthcare Sciences, Plymouth University Peninsula School of Medicine and Dentistry, Plymouth PL4 \\ $8 \mathrm{AA}, \mathrm{UK}$
}

*Corresponding author: Nicola King, School of Biomedical and Healthcare Sciences, Plymouth University Peninsula School of Medicine and Dentistry, Plymouth PL4 8AA, UK, Tel: +44 1752 584969, Fax: +44 1752 586788;

E-mail: Nicola.king@plymouth.ac.uk

\begin{abstract}
Aims: Auscultation is a straight forward and inexpensive method for the preliminary diagnosis of heart valve disease. However, many valve diseases are clinically silent and therefore echocardiography may be the preferred option. In this prospective study we aimed to investigate the sensitivity of auscultation in patients with mitral and aortic valve disease in comparison to Doppler echocardiography.

Methods: 300 consecutive patients with heart valve disease who attended the echocardiography department at Erbil Cardiac Centre between May 2015 and February 2016 were included in this study. Patients were excluded if they were under 15 years of age, had poor window echocardiography, had prosthetic aortic and/or mitral valves, had a history of infective endocarditis, were pregnant or had congenital heart diseases. All of the included patients underwent cardiac auscultation of the mitral and aortic valve, which was carried out by 2 experienced cardiologists. All of these patients were then investigated by transthoracic echocardiography.

Results: 215 mitral valve lesions and 122 aortic valve lesions were detected by echocardiography. The most common lesion detected was mitral regurgitation followed by aortic regurgitation, aortic stenosis and mitral stenosis. Auscultation was only able to detect $51.6 \%$ of the mitral valve lesions and $56.6 \%$ of the aortic valve lesions. There was a significant association between inaudible murmurs and mild valve lesions on echocardiography $(p=0.001)$ and between inaudible murmurs and systolic dysfunction as identified by echocardiography $(\mathrm{p}=0.001)$.

Conclusions: Approximately half of the valve diseases detected by echocardiography were silent clinically.
\end{abstract}

Received Date: February 10, 2017

Accepted Date: March 10, 2017

Published Date: March 17, 2017

Citation: King, N., et al. Cardiac Auscultation Versus Two-Dimensional Transthoracic Echocardiography for detection of Valve Disease in Erbil City. (2017) J Heart and Cardiology 3(1): 7-10.

Keywords: Heart valve disease; Auscultation; Echocardiography

DOI: $10.15436 / 2378-6914.17 .1352$

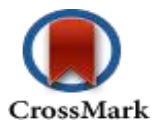

\section{Introduction}

Heart Valve disease accounts for $10 \%$ to $20 \%$ of all cardiac surgical procedures carried out in the United States ${ }^{[1]}$. Approximately two thirds of these operations are for aortic valve replacement associated with aortic stenosis (AS) ${ }^{[1]}$. Mitral valve surgery is mainly performed for mitral regurgitation (MR), whilst most patients with mitral stenosis (MS) are treated by a percutaneous approach ${ }^{[1]}$. There is also a large group of patients with mild to moderate disease, who require accurate diagnosis and appropriate medical management ${ }^{[2]}$.

A murmur is a sound generated when blood travels through vessels or valves in a turbulent or energy-dissipating manner. This can occur in valve and congenital heart disease, where the murmur is usually the major evidence of the abnormality. The murmur is usually detected during a basic cardiac examination by auscultation. Indeed, cardiac auscultation remains the most widely used method of screening for heart disease particularly in resource poor regions and when performed properly is a valuable and cost-effective clinical skill that often establishes the diagnosis, etiology, and severity of heart disease. The bell, when applied gently to the skin, will "bring out" low-frequency sounds and murmurs (e.g. S4 or S3 gallops, diastolic rumble of mitral stenosis). The diaphragm, when pressed firmly against 
the chest wall, will accentuate high-pitched auscultation events (e.g., diastolic murmur of AR, pericardial friction rub) ${ }^{[3]}$. The intensity of a detected murmur corresponds to the loudness or amplitude of the sound wave, and is inversely related to the size of the opening, and directly proportional to the pressure gradient and the amount of blood flow through that opening ${ }^{[4,5]}$. For example, a loud and late-peaking murmur may indicate relatively severe mitral stenosis and a systolic murmur of grade 3 intensity or greater suggests severe AS. It should, however be noted that many murmurs in asymptomatic people are innocent and of no functional significance ${ }^{[6]}$.

In the evaluation of heart murmurs, the purposes of performing a Doppler echocardiogram are to define the primary lesion and its etiology and judge its severity. For example aortic stenosis is said to be severe if the valve area is less than $1.0 \mathrm{~cm}^{2}$, the mean pressure gradient across the valve is greater than 40 $\mathrm{mm} \mathrm{Hg}$, or the jet velocity is greater than $4.0 \mathrm{~m} / \mathrm{s}^{[7]}$. Echocardiography is also used to define hemodynamics, detect coexisting abnormalities, detect lesions secondary to the primary lesion, evaluate cardiac size and function, establish a reference point for future observations, and reevaluate the patient after an intervention.

Despite the widespread utility of cardiac auscultation, some hemodynamically significant regurgitation lesions may be silent. The rationale underpinning the current study was that cardiac auscultation may lack the sensitivity to detect all types of heart valve disease and that this may possibly lead to compromises in patient care. Therefore, the aim of the current study was to investigate the sensitivity of clinical auscultation in comparison to echocardiography in the detection of all types of heart valve disease.

\section{Methods}

This study was conducted in the cardiac center of the Surgical Specialty Hospital in Erbil Governorate. Ethical approval for this study was granted by the human ethics committee of the Surgical Specialty Hospital, Erbil. This study conforms to the declaration of Helsinki regarding research involving human subjects. All subjects gave informed consent.

This prospective study involved 300 patients who attended for echocardiography between May 2015 and February 2016 at the Cardiac Center of the Surgical Specialty Hospital in Erbil. All of these patients had heart valve disease, as detected by echocardiography, and were between 15 - 85 years old.

In the first place all of the subjects were examined by cardiac auscultation. This was conducted by 2 cardiologists. The cardiologists did not know that all of the subjects had heart valve disease. Mitral sounds and murmurs were detected at the left $5^{\text {th }}$ intercostal space mid clavicular line, whilst sounds and murmurs of the aortic valve and aorta were examined at the second right intercostal space and the mid left sternal border. In addition murmur radiation to the neck was examined as an indicator of the systolic ejection murmur of AS and left axilla radiation was examined as an indicator of $\mathrm{MR}^{[4,5]}$.

Following auscultation all of the patients were examined by transthoracic echocardiography using a VIVID E9 ultrasonic machine (USA). M-mode was used to detect structural cardiac abnormalities, chamber dimensions and systolic function.Continuous wave Doppler echocardiography was used to measure the diastolic pressure gradient. The severity of mitral valve stenosis was classified as mild when the mitral valve area (MVA) was more than $2 \mathrm{~cm}^{2}$, moderate when MVA was $1.5 \mathrm{~cm}^{2}$ to $2.0 \mathrm{~cm}^{2}$, severe when MVA was 1.0 to $1.5 \mathrm{~cm}^{2}$ and very severe if the MVA was $1.0 \mathrm{~cm}^{2}$ or less ${ }^{[8]}$. The severity of AR was classified as mild when the jet width was $<25 \%$ of the left ventricular out flow tract (LVOT), moderate when the jet width was $25 \%-64 \%$ of LVOT and severe AR when the jet width was $\geq$ $65 \%$ of LVOT $^{[2]}$. Ejection fraction was calculated using the biplane Simpson method ${ }^{[9]}$. All of the echocardiography staff were blinded as to the results of the auscultation.

Data were analyzed using the Statistical Package for Social Sciences (SPSS, version 19). Chi square test of association was used to compare between proportions. When the expected count of more than $20 \%$ of the cells of the table was less than 5, Fisher's exact test was used. McNemar test was used when comparing the auscultation results with the echocardiography results for the same patients. A p value of $<0.05$ was considered statistically significant.

\section{Results}

Mitral valve disease (either isolated or mixed) was detected by transthoracic echocardiography in a total of 215 patients. Only $111(51.6 \%)$ of these cases were detected by auscultation $(\mathrm{p}<0.001)$. The lesion with the greatest percentage detected by auscultation was MVP and MR, whilst the lesion with the least percentage detection by auscultation was MR (table 1).

Table 1: Comparison of number of mitral valve diseases detected by auscultation compared with echocardiography.

\begin{tabular}{|l|c|c|c|}
\hline Valve lesion & $\begin{array}{l}\text { No. detected } \\
\text { by } \\
\text { auscultation }\end{array}$ & $\begin{array}{l}\text { No. detected by } \\
\text { echocardiography }\end{array}$ & $\begin{array}{l}\text { Percentage } \\
\text { detected by } \\
\text { auscultation }\end{array}$ \\
\hline MR & 71 & 156 & 45.5 \\
\hline MS & 13 & 20 & 65 \\
\hline MR+MS & 11 & 16 & 68.8 \\
\hline MVP & 3 & 6 & 50 \\
\hline MVP+MR & 13 & 17 & 76.5 \\
\hline Total Detected & 111 & 215 & 51.6 \\
\hline
\end{tabular}

$\mathrm{P}=0.001$

Valve lesions that were inaudible by auscultation were most likely to be mild and/or moderate according to echocardiographic criteria for valve severity as shown in table 2 .

These results reveal that auscultation is of low sensitivity in the detection of mitral valve disease. The sensitivity was $51.6 \%$, The specificity $100 \%$, PV positive was $100 \%$ with an agreement rate of $88.3 \%(\mathrm{p}<0.001)$.

A significant number of lesions that were inaudible were found in patients with low systolic function, typically with an ejection fraction of $25 \%$ to $54 \%(\mathrm{p}=0.001)$ as shown in table 3.

Table 4 shows a comparison of the aortic valve lesions detected by auscultation compared to echocardiography. Forty one percent of lesions involving AR were detected by auscultation, $91.7 \%$ of lesions involving AS were detected by auscultation and $50 \%$ of lesions involving AR \& AS were detected by 
auscultation. The lesions, which were most likely to be missed during auscultation, were of mild severity according to echocardiographic criteria. A low ejection fraction (25-54\%) was found in $45 \%$ of the patients whose aortic valve lesions were not detected by auscultation.

Table 2: Number and percent of mitral valve disease which are inaudible during examination according to severity.

\begin{tabular}{|c|c|c|c|c|c|c|c|}
\hline \multirow[b]{2}{*}{$\begin{array}{l}\text { ECHO MITRAL } \\
\text { SEVERITY }\end{array}$} & \multicolumn{7}{|c|}{ ECHO MITRAL FINDINGS } \\
\hline & $\begin{array}{c}\text { MR No } \\
\%\end{array}$ & $\begin{array}{c}\text { MS No. } \\
\quad \%\end{array}$ & $\begin{array}{c}\text { MR+MS } \\
\text { No. } \%\end{array}$ & MVP No.\% & $\begin{array}{c}\text { MR+MVP } \\
\text { No.\% }\end{array}$ & $\begin{array}{c}\text { TOTAL } \\
\text { PAIENTS \% }\end{array}$ & $\begin{array}{c}\text { TOTAL } \\
\text { LESION No. }\end{array}$ \\
\hline \multirow{2}{*}{ Mild } & 33.0 & 5.0 & 2.0 & 2.0 & 3.0 & 45.0 & \multirow{13}{*}{113} \\
\hline & $74.5 \%$ & $10.6 \%$ & $4.3 \%$ & $4.3 \%$ & $6.4 \%$ & $100.0 \%$ & \\
\hline \multirow{2}{*}{ Moderate } & 30.0 & 1.0 & 1.0 & 1.0 & 1.0 & 34.0 & \\
\hline & $88.9 \%$ & $2.8 \%$ & $2.8 \%$ & $2.8 \%$ & $2.8 \%$ & $100.0 \%$ & \\
\hline \multirow{2}{*}{ Severe } & 3.0 & 1.0 & 0.0 & 0.0 & 0.0 & 4.0 & \\
\hline & $80.0 \%$ & $20.0 \%$ & $0.0 \%$ & $0.0 \%$ & $0.0 \%$ & $100.0 \%$ & \\
\hline \multirow{2}{*}{ Mild-Moderate } & 19.0 & 0.0 & 1.0 & 0.0 & 0.0 & 20.0 & \\
\hline & $95.5 \%$ & $0.0 \%$ & $4.5 \%$ & $0.0 \%$ & $0.0 \%$ & $100.0 \%$ & \\
\hline \multirow{2}{*}{$\begin{array}{l}\text { Mild MR \& Moderate } \\
\text { MS }\end{array}$} & 0.0 & 0.0 & 1.0 & 0.0 & 0.0 & 1.0 & \\
\hline & $0.0 \%$ & $0.0 \%$ & $100.0 \%$ & $0.0 \%$ & $0.0 \%$ & $100.0 \%$ & \\
\hline \multirow{2}{*}{ Total Patients } & 85.0 & 7.0 & 5.0 & 3.0 & 4.0 & 104 & \\
\hline & $82.9 \%$ & $6.3 \%$ & $4.5 \%$ & $2.7 \%$ & $3.6 \%$ & $100.0 \%$ & \\
\hline PVALUE* & 0.001 & 0.001 & 0.62 & 0.02 & 0.226 & & \\
\hline
\end{tabular}

*Fisher's Exact Test

Table 3: Correlation between cardiac mitral auscultation and systolic function during echocardiography examination.

\begin{tabular}{|l|c|c|}
\hline $\begin{array}{l}\text { ECHO SYSTOLIC } \\
\text { FUNCTION(EF \%) }\end{array}$ & $\begin{array}{l}\text { Positive } \\
\text { auscultation } \\
\text { No. (\%) }\end{array}$ & $\begin{array}{l}\text { Negative } \\
\text { auscultation } \\
\text { No. (\%) }\end{array}$ \\
\hline $\mathbf{2 5}-\mathbf{3 5}$ & $4(3.6 \%)$ & $11(10.57 \%)$ \\
\hline $\mathbf{3 6}-\mathbf{4 5}$ & $12(10.8 \%)$ & $19(18.3 \%)$ \\
\hline $\mathbf{4 6}-\mathbf{5 4}$ & $22(19.8 \%)$ & $36(34.6 \%)$ \\
\hline $\mathbf{5 5}-\mathbf{7 0}$ & $73(65.77 \%)$ & $38(36.5 \%)$ \\
\hline TOTAL PATIENTS & $111(100.0 \%)$ & $104(100.0 \%)$ \\
\hline
\end{tabular}

Fisher's Exact Test $\mathrm{P}=0.001$

Table 4: Comparison of number of aortic valve diseases detected by auscultation compared with echocardiography.

\begin{tabular}{|l|c|c|c|}
\hline Valve lesion & $\begin{array}{l}\text { No. detected } \\
\text { by } \\
\text { auscultation }\end{array}$ & $\begin{array}{l}\text { No. detected by } \\
\text { echocardiography }\end{array}$ & $\begin{array}{l}\text { Percentage } \\
\text { detected by } \\
\text { auscultation }\end{array}$ \\
\hline $\begin{array}{l}\text { AR (including } \\
\text { isolated AR, } \\
\text { AR\&MR, } \\
\text { AR\&MS, } \\
\text { AR\&MVP, } \\
\text { AR\&bicuspid } \\
\text { aortic valve) }\end{array}$ & 34 & 82 & 41.5 \\
\hline $\begin{array}{l}\text { AS (including } \\
\text { isolated AS, } \\
\text { AS\&MR, } \\
\text { AS\&bicuspid } \\
\text { aortic valve) }\end{array}$ & 33 & 36 & 91.7 \\
\hline AR+AS & 2 & & \\
\hline Total Detected & 69 & \multicolumn{2}{|l}{} \\
\hline
\end{tabular}

$\mathrm{P}=0.001$
Auscultation is of low sensitivity $(56.6 \%)$ in detecting aortic valve lesion with high agreement rate $(94.3 \%)(p=0.001)$. The specificity was $100 \%$, the PV positive $100 \%$ and the PV negative $93.9 \%$.

\section{Discussion}

The greater prevalence of MR in this study compared to other heart valve disease agrees with other studies ${ }^{[10-13]}$. The second most common lesion was AR followed by AS and MS. This is similar to the study by Godown, et a $\left[^{[11]}\right.$ but different from the study by Reddy, et $a l^{[10]}$. These differences could be due to the different ages of the patients involved in these studies with Reddy, et $a l^{[10]}$ enrolling children from 5-16 years old and the current study involving adults.

The reporting indices of different studies in the literature varies with some reporting the sensitivity by auscultation for detecting $\mathrm{MR}^{[10,11,14]}$, one reporting the sensitivity for detecting all mitral valve lesions ${ }^{[15]}$ and two reporting the sensitivity for detecting all valve lesions ${ }^{[12,16]}$. For those reporting the sensitivity of auscultation for detecting MR the values range from $15.9 \%{ }^{[11]}$ to $95 \%{ }^{[17]}$. The percentage detection of MR in the current study is similar to the study by Rahko, et al ${ }^{[18]}$. Reasons for the wide differences in the sensitivity for detecting MR could include the young age of the subjects ${ }^{[10,11]}$ and the small size of the study whose focus was assessing the need for cardiac catheterization rather than the sensitivity of auscultation per $\mathrm{se}^{[17]}$. The greater likelihood of missing mild and moderately severe mitral valve disease is in agreement with another study, which found there was a positive correlation between the ability to detect valve lesions and the severity of the lesion ${ }^{[18]}$. It has also been stated that the ability to detect murmurs is dependent on the years of experience of the clinical examiners ${ }^{[19]}$; however this study employed experienced personnel. 
In the current study the detection of isolated AR and of all aortic valve diseases was similar to the studies of Jost, et $a{ }^{[15]}$ and Rahko, et $a l^{[18]}$ but higher than the studies of Godown, et $a l^{[11]}$ and Stokke, et $a l^{[14]}$. It should be noted however that the study of Godown, et $a l^{[11]}$ was carried out on juveniles where the incidence of AR is known to be rare and AS is known to be absent in this age group ${ }^{[10]}$.

Overall the sensitivity for detecting all heart valve disease was $50 \%$ in the study by Kobal, et al ${ }^{[12]}$, which is very similar to the current study. They went onto state that heart valve diseases that cause a systolic murmur, i.e. AS and MR, were the most accurately detected by auscultation ${ }^{[12]}$. This was also the case in the current study, which was particularly notable in the good detection of isolated AS.

One of the limitations of the current study is the relatively low number of patients enrolled. This number was still bigger than many of the comparator studies ${ }^{[10,12-17]}$ but lower than one study ${ }^{[11]}$. A second limitation is the conduct of this study at a single cardiac center where the proportions of patients suffering different heart valve diseases may not be reflected globally. In this study the 3M Littmann classic stethoscope was used; however there is another newer Littmann stethoscope the Littmann cardiology IV stethoscope which the manufacturer's claim has excellent sensitivity including the detection of "S3 grade 3 heart sound" (http://solutions.3m.co.uk/wps/portal/3M/ en_GB/3M-Littmann-EMEA/Littmann-Stethoscope/). There may have been a slight difference in the detection of murmurs by the 2 cardiologists.

\section{Conclusion}

The results of this study show that clinical auscultation is not very accurate compared to echocardiography for the detection of heart valve disease.

\section{Funding}

This research received no grant from any funding agency in the public, commercial or not-for-profit sectors.

Conflicts of Interest: No conflict of interest.

\section{References}

1. Osorio, R.C., de Freitas, Sousa, F.S., de Andrade, M.N., et al. Valvular heart disease - epidemiology and new treatment modalities. (2016) Interventional Cardiol J 2: 1-11.

Others

2. Mann, D.L, Zipes, D.P., Libby, P., et al. Braunwald's heart disease: a textbook of cardiovascular medicine. (2015) 10th ed Amsterdam: Elsevier.

Others

3. Chizner, M.A. Cardiac Auscultation: rediscovering the lost art. (2008) Curr Probl Cardiol 33: 326-340.

Pubmed $\mid$ Crossref $\mid$ Others

4. Fink, J.C., Schmid, C.H., Selker, H.P. A decision aid for referring patients with systolic murmurs for echocardiography. (1994) J Gen Intern Med 9: 479-484.

Pubmed | Others
5. Bickley, L.S. Bates' Guide to Physical Examination and History Taking. (1999) 7th ed. Philadelphia: Lippincott.

Others

6. Nihoyannopoulos, P., Fox, K., Fraser, A., et al. EAE laboratory standards and accreditation. (2007) Eur J Echocardiogr 8: 80-87.

Pubmed | Crossref

7. Rosenhek, R., Binder, T., Porenta, G. Predictors of outcome in severe, asymptomatic aortic stenosis. (2000) N Engl J Med 343: 611-617. Pubmed | Crossref $\mid$ Others

8. Bonow, R.O., Carabello, B., de Leon, Jr A.C., et al. Guidelines for the Management of Patients With Valvular Heart Disease: Executive Summary A Report of the American College of Cardiology/American Heart Association Task Force on Practice Guidelines (Committee on Management of Patients With Valvular Heart Disease). (1998) Circ 98: 1949-1984.

Pubmed $\mid$ Crossref $\mid$ Others

9. St John, Sutton, M., Otterstat, J.E., Plappert, T., et al. Quantitation of left ventricular volumes and ejection fraction in post-infarction patients from biplane and single plane two-dimensional echocardiograms. A prospective longitudinal study of 371 patients. (1998) Eur Heart J 19: 808-816.

Pubmed $\mid$ Crossref $\mid$ Others

10. Reddy, A., Jatana, S.K., Nair, M.N.G. Clinical evaluation versus echocardiography in the assessment of rheumatic heart disease. (2004) Med J Armed Forces India 60: 255-258.

Crossref $\mid$ Others

11. Godown, J., Lu, J.C., Beaton, A., et al. Handheld echocardiography versus auscultation for detection of rheumatic heart disease. (2015) Pediatrics 135: e939-e944.

Pubmed | Crossref

12. Kobal, S.L., Trents, L., Baharami, S., et al. Comparison of effectiveness of hand-held ultrasound to bedside cardiovascular physical examination. (2005) Am J Cardiol 96: 1002-1006.

Pubmed $\mid$ Crossref $\mid$ Others

13. Spencer, K.T., Anderson, A.S., Bhargara, A., et al. Physician performed point-of-care echocardiography using a laptop platform compared with physical examination in the cardiovascular patient. (2001) J Am Col Cardiol 37: 2013-2018.

Pubmed $\mid$ Crossref $\mid$ Others

14. Stokke, T.M., Ruddox, V., Sarvari, S.I., et al. Brief group training of medical students in focused cardiac ultrasound may improve diagnostic accuracy of physical examination. (2014) J Am Soc Echocardiography 27: $1237-1246$.

Pubmed $\mid$ Crossref $\mid$ Others

15. Jost, C.H.A., Turina, J., Mayer, K., et al. Echocardiography in the evaluation of systolic murmurs of unknown cause. (2000) Am J Med 108: 614-620.

Pubmed $\mid$ Others

16. Roldan, C.A., Shively, B.K., Crawford, M.H. Value of the cardiovascular physical examination for detecting valvular heart disease in asymptomatic patients. (1996) Am J Cardiol 77: 1327-1331.

Crossref

17. Jaffe, W.M., Roche, A.H., Coverdale, H.A., et al. Clinical Evaluation Versus Doppler Echocardiography in the Quantitative Assessment of Valvular Heart Disease. (1988) Circ 78: 267-275.

Pubmed | Crossref

18. Rahko, P.S. Prevalence of regurgitant murmurs in patients with valvular regurgitation detected by Doppler echocardiography. (1989) Ann Intern Med 111: 466-472.

Pubmed | Crossref

19. Kinney, E.L. Causes of false negative auscultation of regurgitant lesions: A Doppler echocardiography study of 294 patients. (1988) J Gen Intern Med 3: 429-434.

Pubmed | Crossref

Journal ISSN: 2378-6914 (online)

Journal E-mail: cardiology@ommegaonline.com

Website: www.ommegaonline.org 